\title{
COLLABORATIVE TRAINING IN RESEARCH METHODOLOGY: A CASE OF MALAYSIA AND LAOS
}

\author{
Wah Yun Low ${ }^{1,2 *}$, Aliyyah Nuha Faiqah Azman Firdaus ${ }^{1}$, Azirah Hashim ${ }^{3}$, Bouasavanh \\ Keovilay ${ }^{4}$, Vong Deuan Osay ${ }^{5}$, Bounthieng Vongsouangtham ${ }^{6}$, Latsanyphone Soulignavong $^{7}$ \\ ${ }^{1}$ Asia-Europe Institute, University of Malaya, Kuala Lumpur, Malaysia \\ ${ }^{2}$ Centre for ASEAN Regionalism, University of Malaya, Kuala Lumpur, Malaysia \\ ${ }^{3}$ Faculty of Languages and Linguistics, University of Malaya, Kuala Lumpur, Malaysia \\ ${ }^{4}$ Ministry of Education and Sports, Vientiane, Lao PDR \\ ${ }^{6}$ International Relations Office, Souphanouvong University, Luang Prabang, Lao PDR \\ ${ }^{7}$ Faculty of Letters, National University of Laos, Vientiane, Lao PDR
}

*Corresponding author: lowwy@um.edu.my

\begin{abstract}
One important aspect of the ASEAN vision is that ASEAN countries strive for equitable economic development and therefore concerted efforts must be made to narrow the development gap between ASEAN countries. This is prioritised in the Initiative for ASEAN Integration which outlines several activities that are designed to assist CLMV countries achieve deeper regional integration while supporting national development priorities and inclusive development. While there has been improvement, there is still significant variance in development achievements. The gaps are wide not only in achievements in income but also in education and health outcomes. This case study provides a description of a Malaysian and Lao collaboration in English language and research methodology training and the challenges faced in doing social science research among Lao academics. The collaboration addresses the developmental divide through knowledge exchange, engagement and collaboration, and capacity building in development between the parties involved.
\end{abstract}

Keywords: research, Laos, Malaysia, capacity building, training

\section{Introduction}

This case study is based on a collaborative project in 2015-2017 between the Asia-Europe Institute, Universiti Malaya and two universities in Laos, the National University of Laos, and Souphanouvong University. The project aimed to strengthen collaboration between Malaysia and Lao academics as well as meet the goals of the ASEAN Economic Community (AEC) and the ASEAN University Network (AUN) for academics in Laos to be highly educated and skilled people for social and economic development of their country. The objective was to develop a Training of Trainers (ToT) programme for English Language Education and Research which can be used effectively by Lao academics. A training programme that met these needs was developed and used in their institutions to test the effectiveness of this programme in order to improve it further.

Laos is one of the last few members to join the Association of Southeast Asian Nations (ASEAN) in the late 1990s and is among those who are 'chasing their neighbours' and have 
much to accomplish in higher education. This struggle is further accelerated by the realization of the AEC and the Initiative of the ASEAN Integration (IAI) Strategic Framework through IAI Workplan Phase II (2009-2015, 2016-2020) that aim to address the development divide and integration of the CLMV countries (namely Cambodia, Laos, Myanmar and Vietnam).

The project aimed to explore the issues and challenges that the Lao academics faced and how both parties collaborated to try to overcome them. The focus of the training was on English academic writing and research methodology concerning English language education. This is seen to be important given the regional efforts in harmonising higher education and the role that English has. In ASEAN countries, "English is being introduced as a compulsory subject into the primary curriculum in all the 10 countries with the exception of Indonesia" (Kirkpatrick, 2010). In many CLMV countries (Cambodia, Laos, Myanmar and Vietnam), the number of schools that use English as medium of instruction is fast growing and might well lead to a situation where the function of English in the curriculum is no longer that of a foreign language, but of a "near universal basic skill" (Graddol, 1997).

The project involved capacity building activities, knowledge transfer and skills development training, as well as a Training of Trainers (ToT) programme to foster a sustainable pool of highly educated and trained academic leaders who will contribute to socio-economic competitiveness for the benefit of their nation. This project also forged strong intercultural ties between Malaysia and Lao PDR, thus further strengthening the network and regional cooperation and integration objectives of the AEC and contributes towards narrowing the development gap between other ASEAN countries in line with the Initiative for ASEAN Integration (IAI).

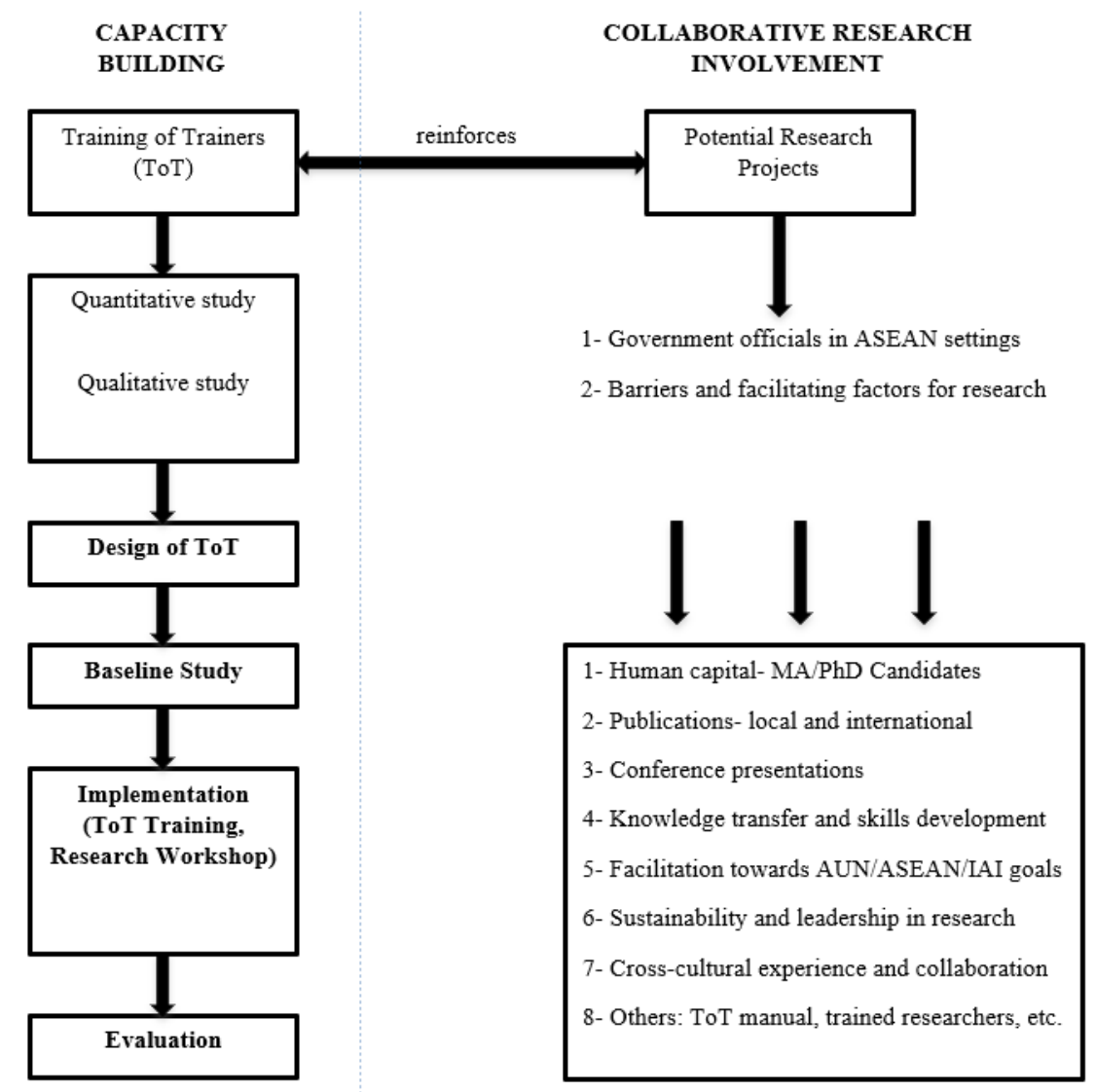

Figure 1: Framework for UM-NUOL ToT Research Programme 
Figure 1 shows the framework for the UM-NUOL ToT Programme. The key to sustainability of any innovation is long term acceptance of the change process through the appropriation of skills, competence and values. This is shown in the Training of Trainers (ToT) methodology as it involved all key partners and several academics and students. Local Lao trainers were engaged as they provided familiarity towards the cultural context as well as the institutional background. Implementation of the ToT was facilitated through academic exchange visits between Universiti Malaya (UM) and the National University of Laos (NUOL). These visits were accompanied by delivery of courses, workshops or seminars for a pool of trained researchers enabling them to be facilitators of learning, not just presenters. The ToT was a jointly developed model/framework between the two partners (UM and NUOL) to facilitate the plan for action.

Dimensions of the ToT consisted of the expert trainers, adult learning theories, sharing of best practices, training processes and the set of tools/techniques for managing participants. The subject content or topics that were covered included knowledge and skills for conducting research, writing for publication, presenting or finding results, ethics in research and publication. The ToT also highlighted the socio-cultural context of ASEAN (ASCC) with emphasis on intercultural learning and understanding of norms, diversity and contextdependent parameters of research for ASEAN community building which narrow the development gap.

Prior to the design of the ToT, a needs analysis survey and focus group interviews were conducted by the research team at NUOL to identify the research needs of the academics in Lao PDR. The survey findings revealed that the academics in Lao PDR are disadvantaged by the following:

- Lack of research experience

- Lack of research knowledge and skills

- Little opportunity to attend research training programmes

- Perception that research is difficult

- Burden of teaching hours and subjects taught

- Insufficient communication in relation to research (unable to access information for research)

The design and implementation of the ToT aimed to meet these needs by producing experienced researchers, organizing research training, and providing effective cooperation between both internal and external organisation and research facilities. At the end of the ToT training, the trained Laos researchers were evaluated based on their training delivery to local participants at another university in Lao PDR.

\section{The Training kit}

The ToT training kit consisted of:

\section{Evaluation form - Participant's feedback}

This is for learners to evaluate the quality of the training workshops/seminars presented by the expert trainers from the University of Malaya. These feedback forms provided input that helped to improve and reframe future development of the workshops/seminars. 


\section{Evaluation feedback/input for ToT improvements}

The feedback gathering sessions were important for the co-development of the ToT module between UM and NUOL. The guiding documents containing the table of contents and the list of topics for every module were provided in advance to the NUOL ToT Committee prior to the UM ToT team's visit to Lao PDR in April 2016. The ToT Committee from NUOL provided feedback for the eleven modules in the following areas - problem areas/difficulties, local situation/examples in Lao PDR, practical implications (application) and other remarks/requests. During one of the visits to Lao PDR in April 2016, the UM and NUOL team had another feedback gathering session to facilitate and elicit more input/contents relevant to ASEAN and the Laotian context for the ToT handbook.

\section{Co-authorship in the ToT Manual}

Regarding authorship, maintaining all slides' main author/contributor' names, including in the templates and a full page that acknowledged the contribution/input from the Laos committee (their names, and affiliations) at the beginning of the handbook was done. This is to highlight that the main contribution comes from the authors of the slides themselves.

\section{Baseline study/Assessment materials}

This is used for pre- and post-training cohorts. The baseline study provided data for further research and as a support facility for ToT review/post-ToT proposals success stories. Within this project, UM also collaborated with the Faculty of Letters, NUOL on joint research publications by putting the process of TOT into practice.

\section{Micro Teaching Evaluation/Reflective journals}

The Micro Teaching (MT) evaluation form was given to all the trainees/facilitators/mentees at the end of the ToT Training Workshop (September 2016) at UM. The ToT Training Workshop was attended by members of the NUOL ToT Committee to participate in the research training for academics from the National University of Laos (NUOL) by expert trainers and to encourage knowledge transfer and exchange between academics from NUOL-UM through the development of the TOT programme. The trainers were divided into two groups with each MT session focusing on a specific module. Each trainee had to choose 3 slides (of specific module) and present for 7 minutes. Performance of the presenters was evaluated by a panel of trainers from the UM team and feedback was given at the end of each MT session. All MT presentations were evaluated according to the following criteria - Familiarity with the content, Clarity of presentation, Communication (voice, eye contact, body language), Interactions with the audience: verbal or non-verbal and Traits of an experienced trainer/researcher, etc. The data from the MT evaluation form was used as a monitoring effort for the effectiveness of the trainers' delivery. Reflective journals were prepared by each member of the UM team to document their personal experiences of conducting/attending training workshops/ seminars/meetings in Lao PDR.

\section{Setting up of an official ToT Committee in this collaboration}

A formal letter of request was sent to the President of the National University of Laos (NUOL) to propose the setup of a project committee at the Faculty of Letters to be involved in the University of Malaya (UM)-NUOL collaborative project for research development through the ToT programme. Details of the project were explained in the letter as well as the functions of 
the ToT committee (to conduct regular meetings (monthly) to discuss planning/issues of TOT for close communication with UM team, to contribute additional content for the TOT modules (UM will be the primary contributor), to participate in a 1-week trainer's training at UM, to plan the implementation of TOT in NUOL i.e. learners, time, resources, etc., to implement research training for faculty members/colleagues (by trained staff/committee) and to evaluate/review implementation results). The proposal of this project committee was in response to the strategic purpose of the ASEAN University Network (AUN) for regional cooperation on academic and higher education collaboration. In addition, it further continues the good relationship and cooperation between both universities, for research leadership and higher education development.

\section{Method in Action}

At the beginning of this project, interviews and surveys were carried out with experienced ToT trainers to devise strategies for the development of an effective ToT training programme for the Laotian participants. Discussions and needs analysis were organised with ToT experts/experienced academics (including the project team members) and the collaborators in Lao PDR. Subsequently, the development of a training programme commenced and the curriculum was constructed by the researcher team based on the feedback/input received from the research instruments. The later part of the project involved the delivery of the ToT programme to selected/identified Laotian academics from the pool of our collaborators. This exchange provided the confidence for the participants/individuals to continue and sustain the training programme at their institutions through knowledge transfer, training and development based on a system of mentors and mentees facilitated by the researcher team and expert trainers. A minor part of this project is the (comparative) analysis of the Laotian academic discourse in research and academic writing. Data was collected from a questionnaire that was distributed to the local respondents who taught/learnedEnglish and had some interest in research writing. Further discussions/communication with the respondents were carried out to clarify findings and results. Focus Group Discussion were conducted to find out the ToT experiences and approaches for capacity building and global engagements in the Lao context. The focus group discussion covered two aspects; (a) Impact of this ToT initiative in order to assess the sustainability factor of TOT for future planning and recommendations and (b) ASEAN Contents. The ASEAN Contents sought to seek suggestions or recommendations on what kind of local Laos content and how they can be included in the TOT presentations and whether the insertion of Laos content was helpful in making the concepts and terms clear.

\section{Challenges faced in implementing the UM-NUOL ToT Programme}

\section{- Challenge 1-Lack of research experience}

Research is new and challenging in Lao PDR even though many of the academics have had experience in conducting research projects and wrote their own theses during their university days. Some of them thought of their research projects during their university course as assignments to complete their degree. Not much emphasis was placed on the purposes of doing research and how they were supposed to conduct it.

Counter Measure 1-Mentor-mentee system: The academics or staff in Lao PDR needed training on how to do research in order to become full-fledged academics because they recognize that teaching and research are deemed important for academics. This was made 
possible through the mentor-mentee system implemented via the ToT programme. Selected academics from NUOL were trained by a group of trainers from UM in the field of social science research. The goal was to prepare them to have a certain body of knowledge, present this effectively, respond to questions and lead activities to reinforce learning. The trained researchers from NUOL were taught to build their confidence, engage the audience, be able to develop learning objectives, assess and evaluate the impact of training initiatives and manage participants with effective techniques- engage different learning styles, create positive learning, manage classroom challenges and others.

\section{- Challenge 2- Lack of research knowledge and skills}

Only a handful of academics and staff in Laos had some knowledge and skills in doing research. Most of them have not been exposed to research and therefore lack the necessary required skills.

Counter Measure 2- Our research knowledge and skills training focused on less familiar research approaches/ techniques. The UM team opted to focus on qualitative research, use of focus group interviews and analysis of qualitative research. Awareness of ethical considerations were also highlighted. The ToT Training manual served as the complete guide on how to conduct research in the social sciences within the ASEAN context, with specific examples from Malaysia and Lao PDR.

\section{- Challenge 3-Little opportunity to attend research training programmes}

Academics or staff in NUOL did not have equal opportunity access to the training. Priority is given to seasoned or senior academics to attend research training programmes whilst the junior academics or staff continue with their daily task. It was also highlighted that places to attend research training programmes are limited (as mentioned in the interview exceprt below):

$\ldots$ เข่บเลิองเอิา ธู้สึกอ่าเข่บใข้ข่อมมาขึ่อบ่อบข

... They asked us to nominate one of our staff as they gave us one seat for the workshop.

(FLE06)

Counter Measure 3-Time-space considerations for ToT implementation must be given ample thought. Research training programmes could be conducted after the examination period and during the university semester break (which means the academics and teaching staff in Laos have less teaching and grading commitments). Postgraduate students should also be invited to attend future capacity building seminars and talks that are scheduled at appropriate hours (eg: not during lecture hours).

\section{- Challenge 4-Perception that research is difficult}

The general view that research is seen as difficult by Lao academics arises because they do not have any or enough experts or individuals who are knowledgeable to supervise them. They also thought that the faculty/university management did not place much emphasis on doing research.

Counter Measure 4- The UM team leveraged on mentoring/ scaffolding involving NUOL lecturers with $\mathrm{MA} / \mathrm{PhDs}$ by instilling positive attitudes towards research, and their implications on the understanding of adult learning theories/learning styles in the trainer's guidelines in the ToT curriculum. By getting them involved directly with the UM expert trainers in various aspects of research, it helped to build and shape their confidence and increase their motivation in doing research. 


\section{- Challenge 5- Burden of teaching hours and subjects taught}

Several academics in NUOL thought that they had more teaching than they were supposed to do. The teaching hours can stretch up to between 11 to 20 hours per week. Some of the academics have to teach from 20 to 40 hours in a week. It would be very difficult for them to spare time to do other tasks such as doing research. These academics also have to teach more than two subjects. There are some academics who have to teach five subjects.

Counter Measure 5- The introduction of action research to the NUOL academics was to introduce the concept of getting started with research in the classroom. By doing this, they could conduct their lessons and do research at the same time. Providing incentives such as research scholarship to bright individuals could also cultivate the research interest among NUOL academics.

\section{- Challenge 6-Insufficient communication in relation to research (unable to access)}

More than half of the staff at the Faculty of Letters, NUOL had hardly accessed the necessary information about research. For example, notices on training, budget, and other related information. Many wished that they had prior information about research funding to be more prepared in developing research proposals and so on.

Counter Measure 6-The promotion of ToT or other research opportunities to relevant networks in the university could be communicated as a long-term research plan for staff with incentives/rewards to those who succeed in securing the research grants. It would be good to keep a database of potential learners by maintaining contact and communication through a broadcasted announcement or e-mail.

\section{Strengths to improve research}

Although the academics faced some limitations, they have certain strengths that would help improve the research capacity at the Faculty of Letters, in NUOL for example, (1) academics recognized the importance of doing research, (2) they were willing to do research, (3) they had a positive attitude towards doing research, and (4) the availability of some research equipment.

\section{Practical Lessons Learned}

Support of the top management is crucial to ease facilitation when conducting training/workshops/seminars in Lao PDR. Recognizing the importance of research will provide more motivation to encourage staff to do research. Good access to Internet is crucial to develop a platform for training. Inclusion of important references which are available online for further reading is necessary. It would be useful to consider a multimodal delivery which includes videos, online-courses, quizzes (some e-learning can be incorporated as activities to reinforce learning/sharing of resources). Availability of a core of people who are familiar with research will aid in the mentoring and coaching initiatives. We need to recognize that capacity building needs long term commitment. Senior academics who have more experiences in doing research could mentor the juniors in research in related areas. Sharing one's expertise with others collegially is one way of passing knowledge from one generation to another generation. Perhaps some kind of a research network within departments and between faculties could be established. A change in the mindset of sharing ideas needs to be encouraged. Collegial performance contributes to the work of the whole team or center or department and ensures a 
future for new generations of researchers. Additionally, it has the benefit of feeding back into improving the activity and performance level of an individual as they learn, reciprocally, from those around them. Providing research seminars that could enhance the research knowledge and capacity is another avenue.

\section{Conclusions}

The purpose of this ToT programme was to empower Laotian academics with the necessary research knowledge and skills in conducting English language teaching (ELT) and educationbased research. Trained academics may become potential leaders/trainers at their respective institutions and can continue similar capacity building activities in a sustainable approach at the local context through knowledge sharing, training and skill development programmes. By engaging these participants in research discussions, we can develop a better understanding about the challenges and issues faced by the academic community in Laos in particular on ELT and their research needs in higher education. Thus, this exchange will facilitate the exploration for strategic sites/areas of cooperation between the nations for academic and higher education development in the ASEAN region. Another UM-led regional and inter-regional endeavour in education that runs from 2017 to 2020 is an Erasmus+ Capacity Building in Higher Education project 'Building Social Research Capacity in Higher Institutions in Lao PDR and Malaysia' (BRECIL). This project aims to build research capacities in Laos universities, enhance research governance in Malaysia and Lao PDR and innovate new research developments through ICT technologies. At the end of the BRECIL project, Lao PDR research capacity is expected to be enhanced as it builds on the Lao National education goals as stated in their National Education law. As for Malaysia, there will be intra ASEAN mobility for researchers and it is clear that the project has goals and aims to fulfil specific actions stated in the "Kuala Lumpur Declaration on Higher Education".

\section{References}

Hashim, A., Yee Chee Leong and Aliyyah Nuha Faiqah Azman Firdaus. (2018). Empowering the Academic Community with Knowledge Skills in ELT and Education-Based Research: Capacity Building in Selected Public and Private Higher Institutions in Cambodia/Laos. In: Shukran Abdul Rahman and Munir Shuib (eds.) Success Stories of Malaysia's Global Reach and CLMV Programme. Kuala Lumpur: IIUM Press.

Muborakshoeva, M. (2015). Impediments to enhancing research within universities in developing context: the case of Pakistani universities. Journal of International and Comparative Education, 4 (1), 1-13.

Graddol, D. (1997). The Future of English: A Guide to Forecasting the Popularity of the English language in the 21st Century. London: The British Council.

Kirkpatrick, A. (2010). English as a Lingua Franca in ASEAN: A Multilingual Model. HongKong: Hong Kong University Press. 